\title{
I ¿Qué partido federal? Lucha de representa- ciones en la Buenos Aires de Juan Manuel de Rosas $^{1}$
}

\author{
Fabián Herrero ${ }^{2}$
}

Si hubiera que señalar hacia 1830 una cuestión clave que despertó el interés público en Buenos Aires, esa podría ser la de los partidos políticos, en cuanto estuvo estrechamente vinculada a temas de muy diversos órdenes, y muy especialmente los que rozan los ámbitos políticos, institucionales y estatales. Si bien el tema ha sido mencionado en más de una oportunidad en diversos estudios del período aquí considerado, no existe todavía un trabajo puntual que se dedique a examinarlo de modo particular. La razón más importante que explicaría tal ausencia debería buscarse quizás en esa imagen extendida que presenta a los partidos, durante la primera mitad del siglo XIX, como grupos de presión generalmente liderados por obstinados caudiIlos que sólo desean obtener el poder provincial o nacional. Se trata, de esta manera, de grupos que, movidos por esos objetivos, se entregan a disputas facciosas (interminables y a veces violentas), en dónde sólo parecen primar los intereses personales.

En el caso del primer gobierno de Juan Manuel de Rosas, es posible mencionar dos cuestiones referidas a los partidos que, (descriptas en estudios generales del período considerado), ofrecen un valioso punto de partida. La primera es la imagen que proponen distintos estudiosos del rosismo, quienes consideran que, luego de la Revolución unitaria de 1828 emerge, muy nítidamente por otra parte, un nuevo escenario enteramente dominado por la

1- El origen del presente estudio es una ponencia presentada en la Jornadas de Homenaje a F. X. Guerra, realizada en el Centro Cultural Borges de Buenos Aires, durante junio del 2004, organizada por la Universidad Nacional de Tres de Febrero. Agradezco los comentarios recibidos en esa oportunidad, como así también los propuestos por el evaluador anónimo de la revista.

2- Conicet (Instituto Ravignani, UBA). 
exclusión unitaria y la hegemonía federal. ${ }^{3}$ Sin embargo, tal predominio no es homogéneo. Es posible definir, entonces, como segunda cuestión, a distintos grupos que actúan dentro de ese dominante partido federal. Aquí, los historiadores se diferencian en la cantidad de grupos que lo conforman. Algunos de ellos han señalado la presencia de dos sectores: los rosistas y los dorreguistas (Barba 1949: 32-33, Lynch 1984: 53). Otro, además de los señalados, presenta a un tercero, integrado por miembros del unitarismo recientemente transformados en federales (Halperin Donghi 1980: 309-310) ${ }^{4}$.

Conviene aclarar que el presente trabajo es una primera aproximación sobre un tema tan amplio como complejo. Intento analizar las representaciones aparecidas sobre los partidos políticos en algunos diarios de Buenos Aires, en los inicios del primer gobierno de Rosas. Y no más que eso; sería preciso ir más allá: saber qué ocurre con dichas corrientes políticas en las distintas dependencias gubernamentales, (ministerios, secretarías). Indagar, asimismo, sus discursos y actividades en las sesiones de la Junta de Representantes, o bien, examinar su acción en las reuniones realizadas en casas de familia, cafés o pulperías. Éstas son algunas de las líneas de investigación de las que sabemos muy poco y que vendrían, sin duda, a iluminar el estudio de los partidos políticos.

Pues bien, ¿cuáles son los objetivos del presente trabajo? Lo que realmente me importa comprender aquí son dos cuestiones: la primera, consiste en saber la perspectiva que cada sector federalista sostiene en relación con los partidos políticos y, en segundo término, explicar las posiciones bien diferentes de cada grupo. Quisiera aclarar, además, que dichos aspectos se estudian a través de los medios periodísticos del período, en un momento político sin mayores conflictos dentro la historia del rosismo.

Antes de explorar dichas diferencias me detendré, sólo un momento, en un aspecto que resultó compartido. Todas las tendencias políticas federales coincidieron en la identificación de algunos de los rasgos más salientes que deberían definir a un partido político. Y en esa perspectiva, sus argumentos formaban parte, como lo ha puesto de relieve Giovanni Sartori, de las

3- En particular puede consultarse, Halperin Donghi 1980, Barba 1949 y Lynch 1984. Resultan también de utilidad los estudios de Celesia 1969, Saldias 1987 e Ibarguren 1984. Es recomendable además la lectura de dos trabajos que reúnen los últimos aportes historiográficos sobre el rosismo: Pagani, Souto y Wasserman 1998 y Segreti, Ferreyra y Moreyra 2000.

4- Me ha resultado asimismo de utilidad la lectura de una investigación cronológicamente posterior a mi objeto de estudio (Lettieri 1999). 
mismas preocupaciones en el mundo occidental. ${ }^{5}$ La irrupción de diversos partidos resulta mal vista porque, generalmente, constituyen la raíz del desorden y la anarquía. Para que no crezcan, entonces, las ramas no deseadas de ese oscuro árbol faccionalista, sus raíces, simplemente, deberían ser eliminadas. A partir de este diagnóstico, prevalece la idea de que sólo debe existir un partido que responda a los requisitos particulares del orden institucional.

¿Qué observo puntualmente en Buenos Aires? En esta provincia predomina ampliamente dicha creencia. En los diarios de los diversos contingentes federalistas, he podido comprobar cómo la mayoría de ellos están de acuerdo en que Juan Manuel de Rosas debe ser el líder de tales fuerzas políticas ${ }^{6}$. Lo que discuten son otras cosas y son las que analizo a continuación.

\section{Los rosistas: una política moderada y conciliatoria para ampliar las bases de poder político}

Desde las páginas de La Gaceta Mercantil, se reproduce y difunde el punto de vista de los llamados rosistas. Puntualmente, y como ocurre con otras cuestiones, dicha perspectiva sobre los partidos debe buscarse en las duras consecuencias producidas por los recientes sucesos revolucionarios. Porque es, precisamente, en ese alterado contexto en el que se afirma que si bien "ha cesado de oírse el estampido del cañón", sin embargo, las dificultades igualmente permanecen en cuanto ese "grito alarmante de las pasiones no se acalla"7. Y a los ojos del redactor, la respuesta al problema de

5- Véase al respecto el excelente estudio de Sartori (1992:17-59). En una perspectiva más general, me fue muy útil para pensar mi trabajo un texto clásico que aborda la vinculación de los partidos como un instrumento de distribución de los cargos públicos por un lado, y, por otro, como portadores de ideales con contenidos políticos, véase Weber (1999: 1078-1079). Menciono algunos trabajos de cuya lectura también me he beneficiado: Panebianco 1990; Duverger 1994 y Todd 2000.

6- En La Gaceta, de orientación rosista, en El Clasificador, de tendencia dorreguista, y en El Mártir o Libre, que representa a los unitarios convertidos al federalismo, es posible señalar dicha posición. En esta línea puede consultarse a modo de ejemplo: "Sin título", La Gaceta Mercantil, 23 de enero de 1830. "Sin título", La Gaceta Mercantil, 24 de febrero de 1830. "Sin título", La Gaceta Mercantil, 10 de mayo de 1830. "Introducción", El Clasificador o El Nuevo Tribuno, Buenos Aires, 1 de julio de 1830. "Triple sinónimo", El Clasificador o El Nuevo Tribuno, 8 de julio de 1830. "Constitución política", El Clasificador o El Nuevo Tribuno, 8 de julio de 1830. Con el mismo título puede consultarse también 10 y 15 de julio. "Libertad de imprenta", El Mártir o Libre, 19 de junio de 1830. "Comunicado. Holgazanes", El Mártir o Libre, 30 de junio de 1830. "Usuras", El Mártir o Libre, 14 de julio de 1830. "Puerto", El Mártir o Libre, 21 de julio de 1830.

7- "Sin título", La Gaceta Mercantil, 5 de febrero de 1830. 
las pasiones sólo tiene una solución. Esta debe basarse en el respeto fiel a los recientes Tratados de Cañuelas y Barracas, firmados en junio y agosto de 1829. Se trata de acuerdos que tienen como principal objetivo restituir el orden legal, lo que permitiría, de ese modo, que las distintas fuerzas políticas tengan la posibilidad cierta y concreta de volver a participar en el espacio público provincial. ${ }^{8}$ El dilema que los porteños enfrentan, en la opinión del redactor, es que ha llegado el momento que dichas fuerzas políticas deben pensar con seriedad dejar de lado sus diferencias para que, de esa manera, resulte posible la construcción de un nuevo orden que, sustancialmente, permita la integración de los hombres que deseen cumplir con las leyes y las instituciones de la provincia.

Dentro de ese marco y desde ese mismo diario, luego se vuelve a lanzar un Ilamado a los porteños que no oculta su tono decididamente dramático: "hoy más que nunca es necesario sacrificarlo todo a la moderación y la concordia". ${ }^{9}$ Ésta es la propuesta rosista: una política legalista que respete los pactos firmados entre los máximos líderes políticos provinciales (Lavalle y Rosas), una política conciliatoria y moderada que permita que los diversos sectores políticos (federales y unitarios) tengan el derecho a participar en la arena pública provincial.

Ahora bien, ¿cuáles son los límites de esta propuesta? Su alcance puede advertirse por ejemplo en la imagen que presenta el diario de los unitarios. Si bien no dejan a un costado las críticas de tono negativo dirigida a los partidarios de la más reciente intentona revolucionaria, en esas críticas no son excesivamente duros, a diferencia de otros diarios porteños, como El Clasificador, El Torito de los Muchachos o El Toro del Once. En esa línea, resulta interesante señalar una carta firmada supuestamente por dos unitarios. Los autores separan por un lado a los "unitarios" que desean el bien y la prosperidad de la provincia, de aquéllos otros "unitarios" violentos que provocaron el terror y la anarquía. De esta forma, señalan una muy clara distancia entre "ellos" que representan el quiebre institucional, de ese "nosotros" que designa a los hombres dispuestos a vivir bajo el inmenso amparo de las leyes. $\mathrm{Y}$ es justamente dentro de esta perspectiva, en donde funciona la metáfora zoológica que supone que ellos "son tigres, nosotros no"10.

8- Véase al respecto el clásico texto de John Lynch (1984: 45- 46).

9- "Sin título", La Gaceta Mercantil, 22 de octubre de 1829. "Continúa el artículo que quedó pendiente en nuestro penúltimo número", La Gaceta Mercantil, 24 de octubre de 1829.

10- "Correspondencia", La Gaceta Mercantil, 18 de diciembre de 1829. Véase también, por ejemplo, El Lucero, 15 de febrero de 1830. 
Como se ve, para los rosistas existen nítidamente dos tipos de unitarios: aquéllos que respetan las leyes de la provincia y por ello no deberían tener inconvenientes para participar en la política local, y aquéllos otros que se han deshonrado con sus crímenes revolucionarios, quienes al tener una actitud contraria al marco legal vigente, deberían ser ubicados fuera del mundo político provincial.

Hasta aquí he descripto la propuesta rosista. Ahora quisiera explicar por qué, para imponerla, utilizan una estrategia que privilegia el acuerdo y la integración de los diversos sectores políticos. Me gustaría mostrar, para decirlo directamente, que esa práctica política acuerdista no es nueva y tiene su pequeña historia en Buenos Aires.

En trabajos anteriores, he podido observar algunos ejemplos. El primero, lo he detectado luego de la derrota de la tendencia confederacionista de 1816: durante esos días rápidamente fueron reincorporados aquéllos que han sido vencidos y que ahora muestran claras señales de lealtad al nuevo orden. Este hecho lo he podido comprobar a través de casos emblemáticos: me refiero, puntualmente, a algunos miembros del Cabildo de Buenos Aires pero también el del mismísimo Gobernador Intendente, todos ellos, una vez resuelto el conflicto que dividió prácticamente en dos a la provincia, fueron restituidos en sus cargos (Herrero 1995). De igual modo, luego del golpe de estado federal de octubre de 1820, fueron también reincorporados una buena parte de las fuerzas cívicas de la ciudad que participaron del alzamiento armado. Y si bien, no lo hicieron en sus antiguas unidades (ya que las mismas fueron en algunos casos cerradas y en otras reestructuradas), sí pudieron hacerlo, en cambio, en las fuerzas militares recientemente creadas. Asimismo, como no todos pudieron gozar de tal beneficio, a los excluidos se les otorgó (a modo de compensación), otros tipos de gratificaciones, como fueros y uso de uniforme militar (Herrero 2003). Las nuevas autoridades, de este modo, cumplieron con la promesa del entonces comandante militar centralista Juan Manuel de Rosas, quien luego de su victoria armada sobre los confederacionistas difundió un muy conocido Manifiesto, en el que afirmaba considerarse amigo de todos los cuerpos cívicos de la ciudad. Fuerzas militares, vale aclarar, que en su gran parte se alzaron en dicha oportunidad. En rigor, se estaba perdonando a aquéllos que, hasta ayer o antes de ayer, lucharon cuerpo a cuerpo en las principales calles porteñas.

Pero esa no fue la única oportunidad en que Rosas participa de una práctica acuerdista luego de conflictivos sucesos revolucionarios. Los Trata- 
dos firmados en 1829 constituyen otro caso similar. A partir de ellos, surge una visión que decididamente prefiere el acuerdo político. Dicha perspectiva puede advertirse con claridad en una propuesta destinada a modificar en parte el sistema electoral. Como hace notar Marcela Ternavasio, se busca reemplazar la competencia de listas que se venían practicando desde la sanción de la ley de 1821 -suprimiendo así la ya tradicional práctica de las candidaturaspor un compromiso basado en una lista única concertada entre Lavalle, líder unitario, y Rosas, líder federal (Ternavasio 1999: 125-126).

De este modo, se ponen en juego dos concepciones divergentes en torno a la política y la representación. Frente a la tendencia que intentaba reemplazar la competencia entre las diferentes listas de notables, se prefiere ahora un régimen de lista unificada, es decir, sólo habría una única lista de candidatos acordada por los partidos y con ella, sostiene la historiadora rosarina, se trataría de lograr la tan ansiada unanimidad de la política en el espacio urbano ${ }^{11}$.

La práctica acuerdista no era nueva, se la utilizó durante la década de 1810, y, el mismo caudillo de Buenos Aires, Juan Manuel de Rosas, fue uno de los que la apoyó y la impulsó durante dos años agitados: 1820 y 1829.

Ahora bien, ¿por qué los rosistas presentan una propuesta moderada y conciliatoria? El principal motivo radica en que dicha estrategia tiene como fin la ampliación y consolidación de la base de poder del flamante gobernador de Buenos Aires. Se quiere integrar a los unitarios porque constituyen una fuerza importante en la provincia, y, porque Rosas encuentra en estos sectores puntos de contacto, como por ejemplo, una prédica pacífica en relación con la política interprovincial. ${ }^{12}$ En este preciso sentido, hay varios indicios que confirman la idea de que los unitarios tienen ciertas condiciones para integrarse, y a su vez, existen claras señales de que constituyen un sector político de consideración.

Por un lado, es conocida la inclusión de prestigiosos unitarios al frente de los Ministerios del primer gabinete rosista: Tomás Guido, en el de Gobier-

11- De hecho, nos aclara Ternavasio, el enfrentamiento entre quienes pretendían suprimirla causó divisiones en el interior de ambos grupos, especialmente el federal. Esto significa que la oposición que llevó a los enfrentamientos más encarnizados no era entre las facciones de unitarios y federales, sino entre quienes defendían una u otra concepción de la representación. ¿Qué efecto tuvo este acuerdo? Resultó un fracaso. Los seguidores de Rosas, si bien momentáneamente no pueden imponer su criterio, seguirán sustentando la lista única hasta imponerla en 1835 (Ternavasio 1999: 125-126).

12- Especialmente, Halperin Donghi 1980.

.36 .

- Revista Quinto Sol, No 8, Año 2004 - 
no y Relaciones Exteriores, y Manuel García en el de Hacienda. Es posible reconocer, en la trayectoria de estos altos funcionarios, una muy activa participación en la política de Buenos Aires formando parte de los gobiernos centralistas durante la primera década revolucionaria que, sustancialmente, se oponían a los proyectos confederacionistas de ese período, vinieran de donde vinieran. Durante la década de 1820, ocupan cargos relevantes tanto en la Ilamada experiencia unitaria como también en el gobierno de Manuel Dorrego. Por último, son unitarios que no han tenido participación directa durante la Revolución de 1828, o lo han hecho de un modo secundario, reintegrándose, rápidamente, a la política provincial en el período de la administración de Juan José Viamonte ${ }^{13}$.

Un segundo indicio que señala en Rosas una línea proclive a la integración política fue mencionado por Halperin Donghi hace un tiempo. Hasta por lo menos el año 1831, la imprenta del Estado porteño sigue ofreciendo a la venta los retratos del ex presidente Bernardino Rivadavia, una de las figuras indudablemente más emblemáticas del partido vencido. Se trata, entonces, de un hecho que supone un clima sin exclusión política. Y justamente en ese marco, el autor de Revolución y Guerra afirma que el caudillo de Buenos Aires manifiesta claramente una línea política de integración hacia algunos miembros del unitarismo ${ }^{14}$.

Hay un tercer indicio, finalmente, por el que es posible señalar muy nítidamente a los unitarios como un grupo político de cierta importancia en Buenos Aires. Para mostrarlo, resulta imprescindible utilizar los datos de un reciente estudio de Jorge Gelman, en el que se propone desentrañar cuáles

13- La filiación unitaria de estos sujetos ha sido destacada por varios historiadores, por ejemplo Halperin Donghi (1980). Hacia 1827, Guido fue Ministro de Guerra del Presidente provisorio Vicente López y Planes. En 1828 fue electo diputado a la Sala de Representantes y poco después fue enviado como enviado extraordinario y ministro plenipotenciario ante la Corte imperial de Río de Janeiro. En octubre fue designado Ministro de Gobierno y Relaciones Exteriores hasta la revolución de diciembre de 1828. Fue nombrado Vocal del Consejo de Estado, en mayo de 1829, y Ministro de Gobierno y Relaciones exteriores en agosto. El gobernador interino Viamonte lo designó nuevamente en el mismo Ministerio después. Rosas lo nombró nuevamente en ese cargo, y en mayo de 1830 fue nombrado comisionado ante la Corte de Brasil para examinar la Constitución política del Estado Oriental. García, por su lado, fue Ministro de Hacienda en Rodríguez en 1821 y de Las Heras en 1824. Fue uno de los que participó en las reuniones que posibilitaron el fin de las hostilidades entre Lavalle y Rosas en 1829, a pedido del primero (Cutolo 1971).

14- "Rosas, si se opone a la fusión de partidos, es en cambio partidario decidido de la incorporación discreta e individual de antiguos adversarios al grupo dominante". Comparto la idea del autor sobre la línea de integración percibida en Rosas, no así en que no promueva, por lo menos, durante 1830 la idea de la fusión de partidos o de sectores (Halperin Donghi 1980: 312). 
son las bases de poder del rosismo en el área rural (Gelman 2003). En este sentido, el autor analiza las listas de unitarios y federales de 1830 y 1831 , que fueron confeccionadas por comisiones constituidas localmente en cada partido de la campaña bonaerense por los representantes del Estado, quienes tenían órdenes precisas de incluir a todos los unitarios y a todos los "vecinos propietarios... conocidos por federales". En dicho relevamiento, sostiene el mismo historiador, fueron censados en la campaña de Buenos Aires más federales que unitarios, contabilizándose un mínimo de 3.263 personas registradas como federales y 780 como unitarios. Es decir, que existe una relación de algo más de cuatro adictos al gobierno por cada opositor entre los sectores más acomodados de la campaña, descontando la adhesión a los primeros por parte de los sectores más empobrecidos ${ }^{15}$. Entre los miembros de la élite, de esta manera, los unitarios constituyen una fuerza menor en relación con el poderío federalista. No obstante, y esto es lo que me interesa señalar aquí para el presente trabajo, aún mantienen un caudal político considerable. Podría decirse, de este modo, que si bien los unitarios no pueden participar como una fuerza política en las elecciones porteñas, ni siquiera pueden editar un diario que defienda sus valores e ideales, sin embargo, aún continúan siendo un sector importante, dentro de los grupos más acomodados.

Esta estrategia política tuvo una duración efímera en Buenos Aires. Sólo permanece hasta fines de 1830. El principal motivo de dicho desplazamiento, indudablemente, debe buscarse en la tensión vivida con el vigoroso frente unitario en el ámbito nacional que, desde Córdoba, ha generado rápidamente el General José María Paz. Dicha tensión hace que la propuesta de fusión de partidos resulte imposible de sostener, en la medida que ambos bloques de poder parecen estar destinados a dirimir sus conflictos en el campo de batalla. Además de los discursos encendidos de los diarios cordobeses por un lado, y, de los porteños y santafesinos por otro, en las distintas provincias las movilizaciones de tropas se registran de modo permanente y sólo están a la espera del inicio del combate. Finalmente, otro evidente indicio

15- El unitario medio hacia 1830-1831 vivía de manera mas sistemática en el norte de la campaña de Buenos Aires y en algunos partidos del sur como Magdalena y Chascomús o de las cercanías al norte de la ciudad de Buenos Aires como San Isidro y Conchas y en los pagos de Areco al oeste. Mientras que los federales predominaban mas en el Sur cercano (se destacan allí Monte y Ensenada) y al exterior del Salado, pero los mayores índices de adhesión al gobierno se encontraban en algunos partidos del oeste (La Guardia y la Villa de Luján), así como en algunos de cercanías como Morón o Flores (Gelman 2003). 
de este nuevo escenario, es el abrupto desplazamiento dentro del gabinete rosista de los Ministros de origen unitario. ${ }^{16}$

\section{Excluir al "otro". Los dorreguistas y algunos diarios de tono popular}

Una segunda perspectiva sobre los partidos políticos es la que ofrecen los sectores más intransigentes. Dentro de ella, se destacan dos corrientes de opinión. Por un lado, los partidarios del ex gobernador Manuel Dorrego, los Ilamados dorreguistas o la vieja oposición popular. Por otro lado, es posible distinguir algunos diarios de tono popular, grupo más difuso que el anterior.

Numerosos artículos escritos por Feliciano Cavia en El Clasificador o Nuevo Tribuno definen la postura de los primeros. En ellos, se alimenta una visión negativa de la prédica conciliadora de los diarios rosistas. En su opinión, dicha conciliación asume la forma de "fusión" o "amalgama" entre el partido federal y el partido unitario ${ }^{17}$. Y si bien advierte que la unión de los partidos en el ámbito nacional resulta el más apropiado, sin embargo, considera que en las actuales circunstancias tal propósito es prácticamente una tarea imposible. La explicación es la siguiente: luego de los crímenes producidos en la reciente Revolución de Lavalle, sus partidarios no pueden ofrecer ningún tipo de garantía sobre su futura acción pública ${ }^{18}$.

Sobre esas convicciones, su punto de vista prefiere claramente las cercanías de la tragedia. Propone simplemente "que un partido concluya con el otro"19; en ese tono decididamente cruel aclara: "vale más llorar en un día las víctimas y desolación que hubieran de hacerse en algunos años" ${ }^{20}$ Finalmente, concluye que "si de este modo no se economiza sangre, al menos se economiza tiempo" 21 . Conviene aclarar que con esta vehemencia (y en calidad de diputado), Cavia sostiene el mismo tipo de discurso en la Junta de Representantes de la provincia. ${ }^{22}$ Tales argumentos pueden leerse también en

16- Para observar este contexto conflictivo producido hacia fines de 1830, véase en particular Halperin Donghi 1980, Barba 1949, Busaniche 1984.

17- Al respecto, puede consultarse:“Triple sinónimo. Clasificación”, El Clasificador o Nuevo Tribuno, 8 de julio de 1830. "Política. Remedios adecuados a nuestros males", El Clasificador o Nuevo Tribuno, 29 de julio de 1830. "Lección para escarmentar", El Clasificador o Nuevo Tribuno, 25 de setiembre de 1830.

18- “Triple sinónimo. Clasificación”, El Clasificador o Nuevo Tribuno, 8 de julio de 1830.

19- "Problemas importantes", El Clasificador o Nuevo Tribuno, 14 de diciembre de 1830.

20- "Problemas importantes", El Clasificador o Nuevo Tribuno, 14 de diciembre de 1830.

21- "Problemas importantes", El Clasificador o Nuevo Tribuno, 14 de diciembre de 1830.

22- Véase sesión del 21 de julio de 1830, en Diario de Sesiones de la Honorable Junta de Representantes de la Provincia de Buenos Aires, año 1830. 
las columnas de El Federal de Santa Fe. Como ya habrá advertido el lector, no se trata de un discurso único y el mismo excede el territorio bonaerense ${ }^{23}$.

Por otra parte y a partir de este eje interpretativo, en otros pasajes de El Clasificador se cuestiona la presencia de unitarios dentro del gobierno de Rosas, ya que ocupan empleos que deberían ser cedidos a los verdaderos federales.

"Se nos ha informado que la autoridad exige irremisiblemente a cualquiera individuo que debe obtener un destino público, aunque sea de los de ínfima categoría, una credencial de su adhesión firme y pronunciada a la causa que sostiene la gran mayoría de la provincia. Parece que la austeridad de la medida llega hasta el extremo de tener que presentar los interesados justificación formal, de que su opinión política es la del sistema federativo. No podemos menos que elogiar un celo tan visible por el progreso de la buena causa. Más en la misma proporción que admiramos este rasgo de política, extrañamos que el gobierno oiga con indiferencia el clamor público, que resuena en todas partes diciendo - AFUERA UNITARIOS DE NOTORIEDAD, DISEMINADOS EN TODOS LOS RAMOS DE LA ADMINISTRACION PUBLICA... Tal es el contraste que no podemos explicar y que quisiéramos ver desaparecer..." (Las mayúsculas son del original) ${ }^{24}$.

Como lo advertí más arriba, una segunda posición es formulado por algunos diarios de tono popular. En sus páginas también se hacen eco de este reclamo ${ }^{25}$. Desde $E I$ Toro de Once se denuncia a simpatizantes del unitarismo que son calificados como asesinos, ladrones, facciosos, destructores de

23- En un tono similar, con ingredientes católicos, se puede hallar este tipo de argumentos en $\mathrm{El} \mathrm{Fe}$ deral de Santa Fe. En la primera época del este diario puede consultarse, "República Argentina", El Federal, 26 de enero de 1829. Allí se afirma que hay que cortar de una vez con la facción unitaria. En la segunda época de este órgano de prensa también puede leerse: "Federales, al arma. Sois el pueblo de Dios...exterminad a esos cananeos, cortadlos por el filo, heridlos por la punta, perseguidlos, acalladlos..." "Observaciones sobre los documentos oficiales insertos en el número anterior", El Federal, 4 de diciembre de 1830 .

24- "Anomalía", El Clasificador o Nuevo Tribuno, 24 de marzo de 1831. Véase también, "Continúa el análisis pendiente. Remedio 8", El Clasificador o Nuevo Tribuno, 25 de agosto de 1830. "Clase militar", Clasificador o Nuevo Tribuno, 14 de setiembre de 1830. En este mismo sentido, uno de los remedios que propone para remediar los males de la provincia, males producidos por los unitarios que protagonizaron la revolución de 1829 es: "Destituir de los empleos civiles y militares a los que se consideren como enemigos de la causa de la restauración." "Política. Remedios a nuestros males", $E l$ Clasificador o Nuevo Tribuno, 29 de julio de 1830.

25- Una lectura rápida de El Torito de los Muchachos, entre setiembre y octubre de 1830, puede ofrecernos ricas evidencias al respecto. Igualmente, puede constatarse una imagen similar en El Toro del Once, véase por ejemplo las ediciones de setiembre a diciembre de 1830 . 
las leyes, asimismo, aquellos, aparecen asociados a profesiones y nacionalidades particulares, por ejemplo, unitarios y pasteleros, unitarios y extranjeros (franceses, gallegos, catalanes) a quienes de ningún modo consideran neutrales ${ }^{26}$. Es de notar que en estas denuncias públicas los señalan con sus "alias" o seudónimos, o se esfuerzan por describir ciertas señales que bien podrían prestarse a confusión. Se denuncia, por ejemplo, a un "godito" que trabaja en una oficina perteneciente a la administración pública, quien es considerado un oportunista porque antes había militado dentro de las filas unitarias. Asimismo y de modo particular, se describe al denunciado indicando (entre otros datos) cómo se viste o brindando precisiones sobre cual es el color de sus ojos. ${ }^{27} \mathrm{Y}$ no sólo señalan a los unitarios que actualmente viven en la ciudad porteña sino también a los que hasta hacía poco tiempo lo eran. La diferencia es importante porque, como tendré oportunidad de hacer ver, a partir de 1829 vemos surgir en Buenos Aires un sector de unitarios que se transforman en federales, formando, de esta manera, una nueva corriente dentro de ese agrupamiento político.

Las denuncias tienen consecuencias muy concretas en la vida cotidiana de los porteños. Ricardo Salvatore, con relación a las formas de adhesión al federalismo, ha mostrado cómo el denuncialismo no sólo era frecuente por aquellos días sino que, además, fue algo muy efectivo. Se puede suponer, entonces, que fueron relativamente reiteradas las sanciones para aquellos que aparecen denunciados (Salvatore 1998: 222 y 223). Este tipo de procedimiento que habita las palabras y las actitudes de los actores, no debería ser considerado como una novedad. En este sentido, traté de probar en otro estudio cómo los órganos de prensa de tono popular y adictos al primer rosismo, como entre otros El Toro del Once, señalan a los diarios de Francisco Castañeda como a uno de sus modelos periodísticos. Me refiero a los diarios que el intransigente padre franciscano editó en Buenos Aires desde 1820, en donde

26- Un epígrafe acompaña todos los números del diario: "Unitarios, no están seguros en casa, cuando el toro está en la plaza".

27- "Otro", El Toro de Once, 2 de setiembre de 1830. Mencionemos un ejemplo más, dos gallegos son tratados de oportunistas ahora porque en tiempos pasados simpatizaban con los unitarios: “...Para conocerlos/daré una señal,/que el uno es cambado/y el otro un bagual./Viudos son los dos,/aunque me han contado,/de que el uno de ellos,/ahora se ha casado..." "Remitido", El Toro de Once, 2 de setiembre de 1830. Otros ejemplos: "La mala vecina", El Toro de Once, 28 de noviembre de 1830. "Remitido", El Toro de Once, 28 de noviembre de 1830. "Oración cotidiana de los unitarios y pasteleros", El Toro de Once, 2 de diciembre de 1830. "Remitido", El Toro de Once, 9 de diciembre de 1830. "Denuncia", El Toro de Once, 9 de diciembre de 1830. 
de manera casi machacona, figuran en el centro de sus páginas la promoción de la política violenta y la delación del "otro" (Herrero 2002).

¿Cómo se explica la posición de los federales intransigentes? En primer término, la hostilidad hacia los unitarios se explica por los daños que estos provocaron, las muertes que causó esa revolución (especialmente la de su jefe), es indudable que jugó un papel fuerte en la actitud de intransigencia y también de "revancha". Pero creo que tal actitud tiene además otros motivos.

Así, en segundo lugar, considero que pretenden disputarle a los federales rosistas algunos puestos dentro del gobierno; de este modo, en medio de la siempre difícil negociación por los lugares de poder, la presencia de los unitarios resulta intolerable. Se trata de la disputa por los empleos del Estado, o, para decirlo claramente, como lo hace El Clasificador, están discutiendo por los llamados "destinos públicos" y en particular por "los destinos militares". Por este motivo, la noción de partido, para el diario de los dorreguistas, está asociado a un uso faccioso del Estado y a denunciar, en este preciso sentido, a los unitarios empleados en dicha administración.

Desde una perspectiva fiscal, Halperin Donghi ha planteado algunas características que forman parte del uso faccioso del Estado rosista. "Los contendientes, dice el autor, usan de su influjo sobre el gobierno para hacer del fisco el tesorero de sus empresas simétricamente facciosas" (Halperin Donghi 1982: 169). En el quinquenio 1830-1834, los gastos en sueldos, cuerpos y establecimientos militares duplican los no militares (\$21.205.312 contra $\$ 10.218 .291$ ); en 1822-1824 aquellos habían excedido a éstos en solo un 17,43\% (Halperin Donghi 1982: 170). Para entender esos gastos, nos recuerda Halperin Donghi, habría que recordar que Rosas vence en el año 1829 con el apoyo de la campaña ganadera. Hasta la obtención del control indisputado del aparato administrativo y sobre todo militar del Estado el desenlace de la victoria no es definitivo. Por ello, se entiende por qué el caudillo de Buenos Aires no puede afrontar la desmovilización de los sectores rurales. Su movilización, como se ha advertido, sólo puede mantenerse "si el Estado a cuya conquista total Rosas aspira, la encuadra y sobre todo las costea" (Halperin Donghi 1982: 170). De esta forma, el gobernador no puede desmovilizar esas fuerzas que recientemente lo apoyaron en su aventura militar, y no puede hacerlo porque fueron, precisamente, los que sostuvieron con su esfuerzo y sacrificio la anhelada victoria armada.

En tercer lugar, la estimulante investigación de Jorge Gelman ya mencionada, nos ayuda a entender porqué en esas denuncias aparecen asociados 
los unitarios con los extranjeros y el comercio (Gelman 2003). Si bien la mayoría de ellos -recordemos que nos referimos a los propietarios-, había nacido en la propia Buenos Aires, una minoría muy consistente estaba compuesta por extranjeros europeos. Asimismo, y en relación con su actividad laboral, predominaban los dedicados a la cría de ganado, quienes constituían la primer minoría; la segunda la formaban los labradores, y, casi un $25 \%$ de los mismos se dedicaban al comercio, lo cual sin ninguna duda representaba un porcentaje muy superior al peso de esa categoría en el conjunto de la población rural y aún en el conjunto de las familias propietarias. Igualmente, si consideramos los niveles de fortuna, es posible señalar que, si bien la mayoría de los unitarios se ubicaba en las escalas intermedias, se destacaba con claridad un buen tercio del total incluido en la categoría de los más ricos propietarios (Gelman 2003). Estos datos nos están mostrando que la acusación formulada a los unitarios, (particularmente percibida en algunos diarios de tono popular) se vincula entonces con su lugar económico y su procedencia natal. No se trata de un discurso sin sentido; hay unitarios en la provincia y los mismos se vinculan con sectores de poder económico y con grupos de origen extranjero.

\section{Los unitarios recién convertidos al federalismo: un sólo partido que figure en una Constitución}

Una tercera posición es enunciada por Rafael Saavedra desde las páginas de El Mártir o Libre. Los partidos políticos, a sus ojos, siempre suponen un elemento de división que finalmente se revela funesta. Cuando esos partidos se convierten en facciones y acceden al gobierno provincial, luego, generalmente, ejercen su poder "destruyendo, violando los derechos de los ciudadanos, eclipsando la supuesta grandeza de su victoria" ${ }^{28}$. De tal modo, un gobierno formado a partir de facciones nunca tendrá consecuencias políticas positivas, porque en él, sólo habrá intereses mezquinos y momentáneos. Es a partir de este sombrío diagnóstico, que debe entenderse por qué el redactor promueve la idea de que dentro del espacio público bonaerense sólo debe existir un partido.

Y hasta aquí, entonces, su argumento no escapa a esa creencia general señalada anteriormente. Sin embargo, hay dentro de este discurso un aspecto

28- "Partidos", El Mártir o Libre, 10 de julio de 1830.

- Instituto de Estudios Socio-Históricos - Facultad de Ciencias Humanas - Universidad Nacional de La Pampa -

.43. 
distintivo: para que realmente dicho agrupamiento político tenga algún tipo de garantías en su desempeño público, debe, inexorablemente, figurar en una Constitución ${ }^{29}$. Es precisamente este último punto lo que lo diferencia tanto de los rosistas como de los dorreguistas, pero también de algunos diarios de tono popular. Hacia 1830, estos sectores se oponen muy firmemente a la idea de redactar y sancionar cualquier tipo de Constitución. Además, porque al promover una línea constitucionalista están convalidando la posición de los unitarios del Interior quienes pretenden organizar de ese modo al país ${ }^{30}$.

Saavedra desea una Constitutición porque, en un clima dominado por la persecución pública (como vimos más arriba), esa Carta Magna serviría, entre otras cosas, para garantizar la formación de una nueva fuerza integrada por miembros de los distintos grupos políticos de la provincia. Y aunque no se lo diga expresamente, se alude, obviamente, a los partidarios de los diversos grupos federales y unitarios. Esta es la propuesta que puede leerse en EI Mártir o Libre.

En el marco de esta visión sobre los partidos políticos debe comprenderse la acusación (por parte de los otros sectores federales) que presenta a EI Mártir o Libre como un diario de partido. Dicho cuestionamiento es reproducido desde los sectores más diversos: como El Lucero y La Gaceta (adictos al rosismo), o por el diario dorreguista El Clasificador. La respuesta por parte de Saavedra no se hizo esperar. En diversos artículos escritos por él o en cartas de suscriptores, se reitera hasta el cansancio que El Mártir no es el órgano de ningún partido ${ }^{31}$. La cuestión parecía seria, y sin duda lo era en la medida que la idea de partido estaba asociada a la de facción y la misma llevaba inexorablemente a la anarquía. Y de ello ningún diario dudaba.

¿Qué explicación tiene este debate? Hay dos motivos que explican dicha calificación y descalificación (de acuerdo a quién leamos). La acusación, en primer lugar, se entiende porque El Mártir o Libre es el único diario en Buenos Aires que no apoya la posición del gobierno provincial con relación a cómo habría que organizar al país. De este modo, cuestiona a todos los

29-“Partidos", El Mártir o Libre, 10 de julio de 1830.

30- Esta discusión entre los sectores rosistas y dorreguistas frente a las posiciones constitucionalistas de los partidarios de Paz, la he analizado en Herrero (2004).

31- "El Clasificador o Nuevo Tribuno", El Mártir o Libre, 17 de julio de 1830. "Posta al Lucero y Nuevo Tribuno", El Mártir o Libre, 17 de julio de 1830. "Al Tribuno y Lucero", El Mártir o Libre, 21 de julio de 1830. "Constitución”, El Mártir o Libre, 28 de julio de 1830. “Al Tribuno", El Mártir o Libre, 31 de julio de 1830. 
órganos de prensa porteños que no quieren que la nación se organice constitucionalmente. $Y$ en esta precisa línea, reivindica a todas aquellas figuras que tienen o tuvieron como principal objetivo político la idea de organizar la nación a partir de medios constitucionales. No sólo menciona a Rivadavia, sino que, además, lo que resulta menos tolerable es la reivindicación tanto de Lavalle como de José María Paz ${ }^{32}$.

En segundo lugar, el rechazo de los principales diarios porteños hacia El Mártir debe buscarse en el amplio apoyo que, desde sus páginas, se ofrece a los partidarios del unitarismo. Además de las reivindicaciones mencionadas, propone un decreto especial (un amplio indulto) para los unitarios que participaron de la Revolución de 1828. Tal medida beneficiaría:

"a una porción de jóvenes llenos de servicios militares, contraídos en continuadas e interrumpidas campañas, cuya buena conducta les hacían acreedores al premio consiguiente a sus pasadas fatigas. El error de eso, en concepto del editor, es en algún modo excusable; y él entrevé bien cercano el día, en que por un decreto especial sean todos llamados y considerados en sus propios destinos. Teniéndose para ello presente: que el régimen de la subordinación militar en que están constituidos, no les permitía sino obedecer sin inquirir ni preguntar, y que el tiempo de indecibles desgracias que han sufrido y están en la actualidad sufriendo, es suficiente a purgar el error, a que los han conducido los autores de aquel funesto día. Su Patria los Ilamará bien pronto, y acogiéndose en su seno como madres tiernas les dispensará sus caricias, declarándolos acreedores a los premios correspondientes, al tiempo de servicios que han prestado... Su extravío, pues, debe conceptuarse suficientemente expiado con el inmenso mar de privaciones e infortunios en que desgraciadamente se ven sumergidos" ${ }^{\prime 33}$.

En el mismo artículo, el redactor aclara ahora que no debe entrar en ese decreto especial el señor Lavalle porque fue quien encabezó la última Revolución.

Como ya habrá advertido el lector, si desde La Gaceta se hacía una separación entre los unitarios legales de aquellos otros que aparecen como violentos, con el concreto propósito de lograr una conciliación, por ese mismo camino, El Mártir o Libre, llega aún mucho más lejos. Pide un amplio in-

32- "Correspondencia”, El Mártir o Libre, 7 de julio de 1830. "Posta Al Lucero y Nuevo Tribuno", El Mártir o Libre, Buenos Aires, 17 de julio de 1830.

33- "Orden”, El Grito de los Pueblos, 28 de setiembre de 1831. 
dulto para esos jóvenes militares que participaron en la Revolución unitaria, porque dichos combatientes, aclara Saavedra, actuaron bajo "el principio de la subordinación". De tal modo, sostiene que se los persigue por algo que hicieron bajo aquel principio, y por ello se suspenden sus derechos civiles, se los destituye de los empleos civiles y militares o bien se los destierra. Dentro de esta perspectiva, se entiende porqué critica puntualmente al redactor de $E I$ Clasificador cuando, una y otra vez, manifiesta una fuerte voluntad de "arreglar las cosas matando unitarios" ${ }^{\prime 34}$. En este preciso sentido, para Saavedra, Feliciano Cavia se parece excesivamente a "Robespierre", en la medida que pretende solucionar los problemas actuales exterminando unitarios o bien destituyéndolos de sus empleos en la administración pública ${ }^{35}$.

Llegado a este punto, el discurso de El Mártir o Libre resulta sumamente original como peligroso. En primer lugar, porque hacia 1830 es el único órgano de prensa en Buenos Aires que propicia la sanción de una Constitución $y$, al mismo tiempo, porque cuando alude a los gobiernos despóticos (aquéIlos que gobiernan con facultades extraordinarias), no ahorra ninguna crítica de tono negativo (Herrero 2004), razones por las cuales el diario es clausurado ese mismo año. En segundo lugar, dicha originalidad resulta al mismo tiempo altamente peligrosa en la medida que sus posiciones se parecen a las que difunden los diarios de Córdoba, quienes (insisto una vez más) defienden la formación de un poder alternativo y por esos días mantienen una posición muy tensa con las provincias federales del litoral que, justamente, tienen en Rosas a una de sus figuras más salientes.

\section{Cada cual a su juego y todos con el gobernador Rosas. A modo de conclusión}

Los historiadores que se han dedicado a estudiar el período aquí considerado, han descripto con entera claridad la hegemonía del federalismo a

34- "Letrilla sacada de un manuscrito. A los filosofastros Legisladores.", El Mártir o Libre, Buenos Aires, 11 de agosto de 1830 .

35- "Correspondencia", El Mártir o Libre, 11 de agosto de 1830. En esta precisa línea debe leerse la exposición del Representante Cavia en la Sala de Representantes de Buenos Aires, en donde pide el exterminio de los enemigos unitarios, considerando que las facultades ordinarias no son suficientes para atrapar a los "asesinos". Por este motivo, considera sumamente necesario saltear los trámites legales y otorgar al gobernador (como finalmente se hizo) las conocidas facultades extraordinarias. "Impugnación a la alocución el Honorable Diputado D. Pedro Feliciano Cavia, en la sesión del 21 de julio del corriente, que se registra en el número 10 del Clasificador", El Mártir o Libre, 31 de julio de 1830. 
partir de 1829 y la aparición de distintas corrientes de opinión dentro de él. Mi aporte historiográfico fue mostrar, en primer lugar, que hacia 1830 los distintos sectores federalistas coinciden en que debe existir una sola fuerza política de esa orientación ideológica liderado por Juan Manuel de Rosas, quien aparece como el líder natural para ejercer dicha función. Para decirlo en otras palabras, nadie discute el liderazgo del caudillo de Buenos Aires, eso sucederá más adelante, precisamente cuando en 1832 Balcarce y Rosas se disputen el poder ${ }^{36}$. De esta manera, como ocurrió en otras ocasiones (pienso por ejemplo en 1816 o 1820), el líder que emergió a la luz pública como el que ha dado una respuesta política y militar a los sucesos revolucionarios, apareció liderando el partido y, por consiguiente hegemonizó el poder provincial.

Lo que se debate en particular son los requisitos de ese partido: cómo debe actuar y quién debe formarlo. Para los rosistas, sería una suerte de amplio tinglado en donde deben refugiarse todos los sujetos que deseen respetar las actuales autoridades de la Provincia. De este modo, los distintos sectores federales y unitarios podrían formar parte de él, si cumplen con aquella condición. La integración de esos diversos contingentes, se explica, sin lugar a dudas, porque Rosas considera necesario para el buen funcionamiento del nuevo orden político la ampliación de su base de poder. Dicha estrategia se recuesta sobre una práctica acuerdista que no es nueva en Buenos Aires y que registra varios antecedentes al respecto.

Como representante de los unitarios convertidos recientemente al federalismo, Rafael Saavedra, por su parte, cree necesario que el partido federal debe estar conformado por los diversos grupos políticos de la provincia y, además, se muestra convencido de que tal punto de vista debería figurar en una constitución, único reaseguro en un clima de persecución política. De esta manera, coincide con el rosismo en la medida que su postura prefiere la moderación y la conciliación. Sin embargo, su firme creencia constitucional lo aleja de los sectores rosistas. Y lo aleja de un modo diría brutal, ya que fue la cuestión que motivó la clausura de El Mártir o Libre.

Los sectores más intransigentes del partido federal, los dorreguistas y algunos diarios de tono popular, pretenden que se excluya a los unitarios del espacio político bonaerense. Los primeros, desean que las fuerzas federales estén conformadas por los militantes de esa orientación ideológica que han mostrado lealtad a su causa, y en este sentido, cuestionan al gobierno, por-

36- En relación con esa disputa véase Halperin Donghi 1980. 
que al ofrecerles a los unitarios puestos civiles y especialmente militares, se muestra proclive a integrarlos.. Algunos diarios de tono popular hacen por su parte una doble impugnación: a la ya mencionada y añaden una segunda. Critican, puntualmente, a los unitarios que pertenecen a los sectores extranjeros y que se dedican al comercio en la ciudad. Esa doble impugnación está vinculada no solo a la disputa por los empleos de la administración pública, sino también al resentimiento hacia aquellos que se dedican a las tareas comerciales. Bien podría suponerse, para terminar, que el discurso de los sectores intransigentes parece estar dirigido tanto a los sectores populares como a los grupos más radicalizados.

\section{Resumen}

En este trabajo, analizo las distintas perspectivas que sobre los partidos políticos enuncian tres sectores federales durante el primer gobierno de Juan Manuel de Rosas. Razones políticas, económicas e institucionales subyacen en el discurso de esos grupos federalistas. Tal disparidad de intereses y argumentos resulta de especial importancia para entender los motivos de la existencia de tales divisiones dentro del partido federal.

\section{Palabras claves}

Buenos Aires - federalismo - partidos - poder - rosismo.

\section{Abstract \\ Which Federal Party? Struggle for representations in Juan Manuel de Rosas' Buenos Aires.}

In this paper, I analyse the different perspectives that are enunciated by three federal lines about political parties, during Juan Manuel de Rosas' first government. Political, economical and institutional reasons underlie the speech of those federalist groups. Such disparity of interests and arguments assume special importance to understand the causes of the existence of such divisions inside the federal party.

\section{Key words}

Buenos Aires - federalism - parties - power - rosism. 


\section{Referencias Bibliográficas}

*BARBA, Enrique (1949), "El primer gobierno de Rosas. Gobiernos de Balcarce, Viamonte y Maza", en: Ricardo Levene, Historia de la Nación Argentina. Desde sus origenes hasta la organización definitiva en 1962, Academia Nacional de la Historia, Buenos Aires, vol. VII, pp. 31 a 112.

*BUSANICHE, José Luis (1984), Historia Argentina, Buenos Aires, Ediciones Solar. *CANSANELLO, Carlos (2003), De súbditos a ciudadanos. Ensayo sobre las libertades en los orígenes republicanos. Buenos Aires, 1810-1852, Buenos Aires, Ediciones Imago Mundi.

*CELESIA, Ernesto (1969), Rosas. Aportes para su historia, Buenos Aires.

*CUTOLO, Vicente (1971), Nuevo diccionario biográfico argentino, Buenos Aires. *DUVERGER, M(1992), Los partidos políticos, México, Fondo de Cultura Económica. *GELMAN, Jorge (2003), "Unitarios y federales. Control político y construcción de identidades en el primer rosismo", ponencia en: $I X$ Jornadas Inter Escuelas y Departamentos de Historia, Córdoba.

*HALPERIN DONGHI, Tulio (1980), Historia Argentina. De la Revolución de independencia a la confederación rosista, Buenos Aires, Paidós.

*HALPERIN DONGHI, Tulio (1982), Guerra y finanzas en los orígenes del Estado Argentino (1791-1850), Buenos Aires, Editorial de Belgrano.

*HERRERO, Alejandro (2004), La política en tiempo de guerra. La cultura politica francesa en el pensamiento de Alberdi (1837-1852), Buenos Aires, EDUNLA. *HERRERO, Fabián (1995), "Buenos Aires, año 1816. Una tendencia confederacionista", en: Boletín del Instituto de Historia Argentina y Americana Dr. Emilio Ravignani, $\mathrm{n}^{\circ}$ 12, Buenos Aires, pp. 7-32.

*HERRERO, Fabián (1995), "Constitución y federalismo. Una opción de los unitarios convertidos al federalismo, durante el primer gobierno de Juan Manuel de Rosas", inédito.

*HERRERO, Fabián (2002), "Francisco de Paula Castañeda (1776-1832). Sobre algunas líneas "bárbaras" en su discurso público", en: CALVO Nancy, DI STEFANO, Roberto y GALLO Klaus (idea y coordinación), Los curas de la Revolución. Vidas de eclesiásticos en los orígenes de la Nación, Emecé, Buenos Aires, pp. 247-264.

*HERRERO, Fabián (2003), "Un golpe de estado en Buenos Aires, octubre de 1820", en: Anuario del IESH, n.18, Tandil, provincia de Buenos Aires, pp. 67-85. *LETTIERI, Alberto (1999), "Repensar la política facciosa: la Conciliación de los partidos políticos de 1877 en Buenos Aires", en: Boletín del Instituto de Historia Argentina y Americana "Dr. Emilio Ravignani", Tercera serie, no 19, 
Buenos Aires, pp. 35-80.

*LYNCH, John (1984), Juan Manuel de Rosas, Emecé, Buenos Aires.

*IBARGUREN, Carlos (1984), Vida de Juan Manuel de Rosas, Buenos Aires.

*MYERS, Jorge (1995), Orden y virtud. El discurso republicano en el régimen rosista, Bernal, Universidad Nacional de Quilmes.

*PAGANI, Rosana, SOUTO, Nora y WASSERMAN, Fabio (1998), "El ascenso de Rosas al poder y el surgimiento de la Confederación (1827-1835), en: * GOLDMAN, Noemí (dir.) Nueva Historia Argentina. Revolución, república, confederación (1806-1852), Buenos Aires, Planeta, pp.283-321.

*PANEBIANCO, Angelo (1990), Modelos de partido, Madrid, Alianza.

* RATTO, Silvia (2003), Vecinos e indígenas en la conformación del espacio fronterizo, Buenos Aires.

*SALDIAS, Adolfo (1987), Historia de la Confederación Argentina, Buenos Aires. *SALVATORE, Ricardo (1998), "Expresiones federales: formas políticas del federalismo rosista”, en: GOLDMAN Noemí y SALVATORE Ricardo, Caudillismos rioplatenses. Nuevas miradas a un viejo problema, Eudeba, Buenos Aires, pp. 189-222.

*SARTORI, Giovanni (1992), Partidos y sistemas de partidos, Alianza Universidad, Madrid.

*SEGRETI, C., FERREYRA, A. I., MOREYRA, B.(2000), “La hegemonía de Rosas. Orden y enfrentamientos políticos (1829-1852), en: Academia Nacional de la Historia. Nueva Historia de la Nación Argentina. Tomo 4. Buenos Aires, Planeta, pp. 379-426.

*TERNAVASIO, Marcela (1999), "Hacia un régimen de unanimidad. Política y elecciones en Buenos Aires, 1828-1850", en: SABATO, Hilda (coordinadora), Ciudadanía política y formación de las naciones. Perspectivas históricas de América Latina, México, Fondo de Cultura Económica, pp 119-141.

*TERNAVASIO, Marcela (2002), La Revolución del voto. Política y elecciones en Buenos Aires, 1810-1852. Buenos Aires, Siglo Veintiuno editores Argentina. *TODD, Allan (2000), Las revoluciones, 1789-1917, Madrid, Alianza Editorial. *WEBER, Max (1999), Economía y Sociedad. Esbozo de sociología comprensiva, México, Fondo de Cultura Económica.

\section{Recibido: 09/06/04}

Aceptado: 23/07/04 